\title{
On the Consumption of Marshmallow Residues, an Atypical Food Item, by Anolis cristatellus Duméril and Bibron, 1837 in Puerto Rico ${ }^{1}$
}

\section{Norman Greenhawk ${ }^{2}$}

Abstract: An Anolis cristatellus lizard is reported eating marshmallow residues. This appears to be the first such report ever of an anole eating a human-created food item.

Key Words: Anolis cristatellus, atypical food, marshmallows, Puerto Rico

Although anoles are generally considered insectivorous, frugivory has been observed in seventeen species (Herrel et al. 2004). Nectarivory has been noted in anoles as well, and additional research is showing that frugivory and nectarivory are part of the diet of many West Indian anoles (Losos 2009). There has even been an observation of $A$. sagrei Duméril and Bibron, 1837 consuming the sap of a banana plant (Norval and Mao 2013). Frugivory has been observed in the Puerto Rican species Anolis stratulus Cope, 1861; A. gundlachi Peters, 1877; A. krugi Peters, 1877; and A. cristatellus Duméril and Bibron, 1837 (Vega-Castillo 2014, Vega-Castillo and Cuevas 2009, Vega-Castillo and Puente-Rolón 2011) and nectivory has been observed in A. evermanni Stejneger, 1904 (Colón Archilla 2010). Anole frugivory is thought to play a role in seed dispersal in Puerto Rican forests (Vega-Castillo and Cuevas 2009).

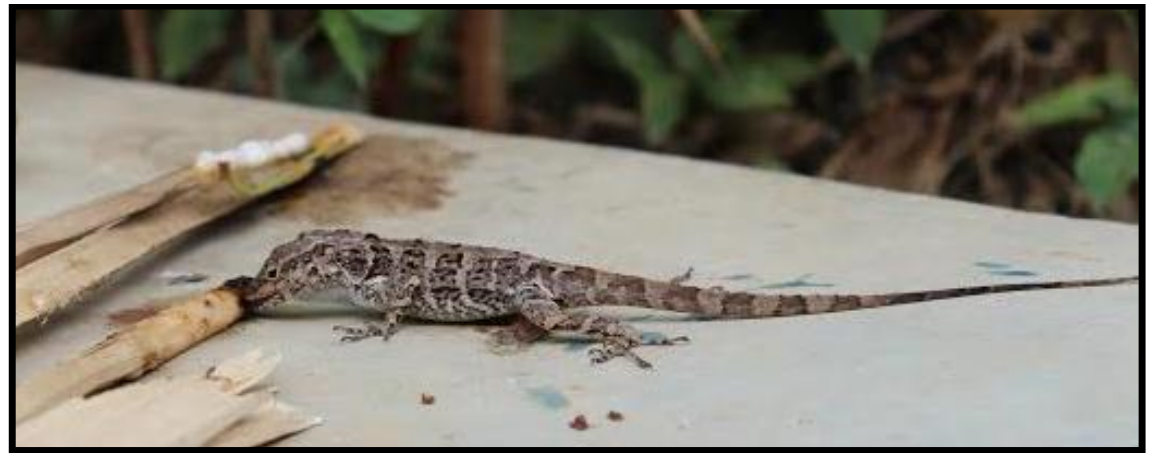

Figure 1. A male Anolis cristatellus feeding on marshmallow residues. Estimated size of the lizard, from tip of snout to vent, $\sim 7 \mathrm{~cm}$.

\footnotetext{
${ }^{1}$ Submitted on December 12, 2014. Accepted on December 13, 2014. Last revisions received on December 20, 2014.

${ }^{2}$ Tropic Ventures Research and Education Foundation, Las Casas de la Selva, HC-63, Buzón 3879 Patillas, Puerto Rico 00723. E-mail: greenhawk81@ gmail.com
}

DOI: 10.9784/LEB2(4)Greenhawk.01

Electronically available on January 10, 2015. Mailed on January 10, 2015. 
On March $18^{\text {th }}, 2014$, at approximately 09:00, I observed an adult male Anolis cristatellus eating the remains of a marshmallow that had been roasted over a campfire the night before. The remains were on the end of stick that had been discarded on an outdoor table at the homestead of Las Casas de la Selva (http://eyeontherainforest.org/), a sustainable forestry projectin the Carite Forest region of Patillas, Puerto Rico. The anole licked the charred marshmallow residue and four times bit the end of the stick. This feeding event took place for eleven minutes, until one of the observers accidentally startled the anole.

Although no insects were observed, is possible that the stick initially had insects feeding on the residue, and this is what attracted the anole, which continued to feed after consuming the prey items. Alternatively, it is possible that the anole intentionally sought out the marshmallow residue. I believe this is the first record of an anole consuming a human-manufactured food item.

\section{Acknowledgements}

I thank George LoCasio for his photograph of A. cristatellus and Tropic Ventures Research and Education Foundation for providing research support. Jan Zegarra (United States Fish and Wildlife Service, CaboRojo, Puerto Rico), Rita Cáceres (University of Puerto Rico, Río Piedras), as well as three anonymous reviewers read the manuscript and offered constructive comments.

\section{Literature Cited}

Colón Archilla, A. D. 2010. Nectarivory in Puerto Rican Emerald Anoles (Anolis evermanni). IRCF Reptiles \& Amphibians 17(3):144-145. http://alfredocolon.zenfolio.com/anolis_evermanni.pdf

Herrel, A., B. Vanhooydonck, R. Joachim, and D. J. Irschick. 2004. Frugivory in polychrotid lizards: effects of body size. Oecologia 140:160-168. http://dx.doi.org/10.1007/s00442-004-1558-7

Losos, J. 2009. Lizards in an Evolutionary Tree: Ecology and Adaptive Radiation of Anoles. University of California Press. Berkeley, California, USA. 528 pp.

Norval, G. and J.-J. Mao. 2013. An instance of a brown anole (Anolis sagrei Duméril \& Bibron, 1837) feeding on the sap of a banana plant (Musa sapientum L.). Herpetology Notes 6: 501502 . http://www.herpetologynotes.sehherpetology.org/Volume6_PDFs/Norval_HerpetologyNotes volume6_pages501-502.pdf See also this link, http://www.anoleannals.org/2013/04/22/anoles-feeding-on-liquids-please-help/

Vega-Castillo, S. I. 2014. Ecological interactions of Anolis cristatellus and Anolis krugi in two secondary tropical karst forests at the northern karst belt of Puerto Rico. Occupancy estimates and degree of omnivory/frugivory. Ph. D. Dissertation. Universidad de Puerto Rico, Río Piedras. 206 pp. http://repositorio.upr.edu:8080/jspui/handle/10586\%20/442

Vega-Castillo, S. I. and E. Cuevas. 2009. Frugivory in Puerto Rican Anolis lizards and its possible effects on seed dispersal in tropical dry and moist forests on karst. http://repositorio.upr.edu:8080/jspui/handle/10586\%20/198 External Scientific Advisory Committe (ESAC). University of Puerto Rico. Río Piedras Campus. Poster presentation.

Vega-Castillo, S. I. and A. R. Puente-Rolón. 2011. Anolis species frugivory. Herpetological Review 42(4):598-599. 